\title{
HUMANITAS
}

\section{Role of ankle block in the foot surgery.}

E. Barbara22,G. Voto² , M. Chiaranda11, N. Di Spigno², A. Grosso², G. Di Palma1', M. Corbisiero1

1 Scuola di Specializzazione in Anestesia, Rianimazione e Terapia Intensiva - Università degli Studi dell'Insubria 2 I.C. Humanitas Mater Domini - Castellanza ( VA )

\section{INTRODUCTION}

This prospective observational study examins the role of ankle block in foot operations.

\section{OBJECTIVES}

We want evaluate the efficacy of ankle block in this kind foot's surgery. Patients walk soon after surgery time and we have evaluated pain at rest and on movement. Still we have considered the adverse events: nausea, vomiting, hematoma in site of hetics toxicity, ,local infections.

\section{METHOD}

We enrolled 212 patients, ASA I-III. We measured onset/offset time of block, preintra-, and post-operative hemodynamic parameters (heart rate and blood
pressure) total operation duration, the degree of sedation, post-operative pain severity through visual analogical scale (VAS) at 6-12-24 $\mathrm{h}$ and 1 month after operation, the need for rescue analgesia and any complications/side effects.

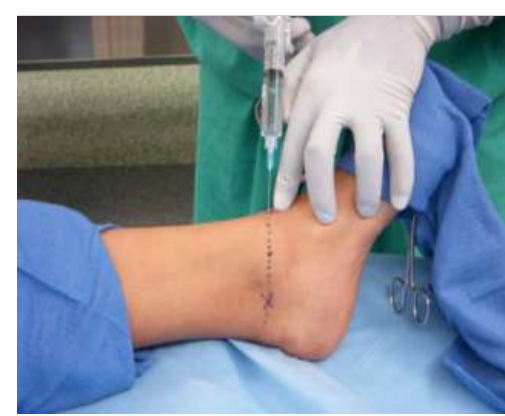

\section{RESULTS}

There were no statistically significant differences in the measures pre-, intraand post-operative of blood pressure, and heart rate (variation $<30 \%, \mathrm{p}=0.12$ and $p=0.39$ ). VAS at rest $<3$ in $94 \%$ of patients was attained in the worst time at $12 \mathrm{~h}$ after surgery (graph 1). Also VAS on movement (walking test 30 meters) ( 3 in $93 \%$ (Graph 2 ). 14\% of patients suffered nausea and vomiting and $4 \%$
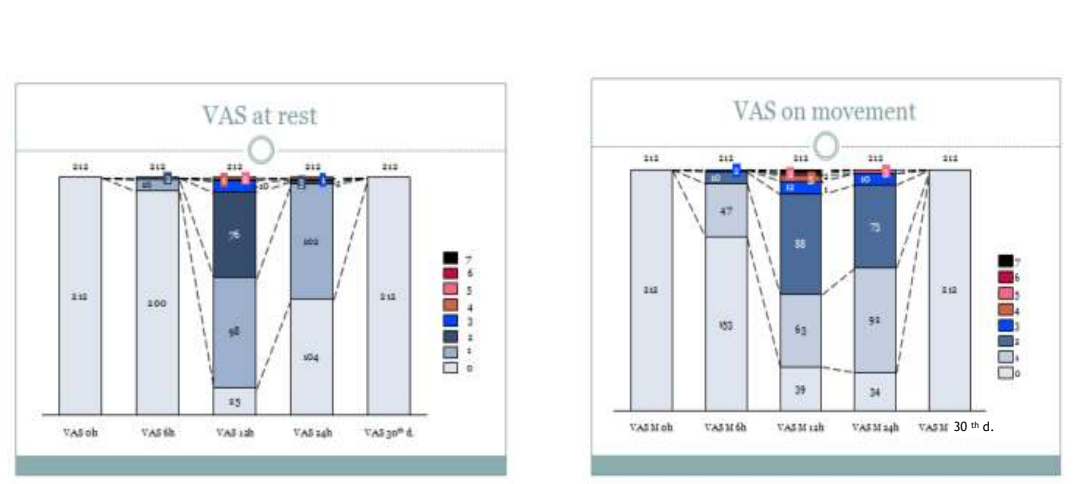

VAS at rest ( Graph 1 , vas on movement ( Graph 2

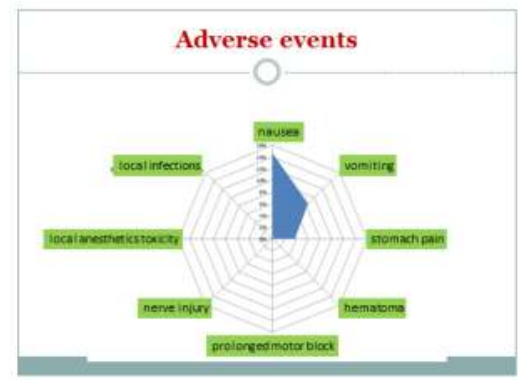

\section{CONCLUSIONS}

Ankle block was effective for percutaneous surgery of foot and for the management of pain post-operative and the adverse events were limited. Also the ankle block allows early deambulation of patients.

In conclusion, for this kind of foot surgery the ankle block we considered a optimal In conclusion, for this kind of foot surgery, the ankle
tecnique in cosideration of the best patient outcome.

\section{ACKNOWLEDGEMENTS}

Thanks to the University Professor Maurizio Chiaranda

\section{REFERENCES}

'O'Donnell B.D., lohom G. Regional anesthesia tecniques for ambulatory orthopedic surgery. Curr. Opin. Anaesthesiol. 2008; 21: 723-728 2Tran D., Clemente A., Finlayson R.J. A rewiew of approaches and techniques for

CONTACT INFORMATION

ENRICO BARBARA, MD

C. Humanitas Mater Domini

Via Gerenzano ,

E-mail: enrico.barbara@materdomini. 